\title{
Clinical utility of tumor genomic profiling in patients with high plasma circulating tumor DNA burden or metabolically active tumors
}

Cathy Zhou ${ }^{1 \dagger}$, Zilong Yuan ${ }^{2,3 \dagger}$, Weijie Ma ${ }^{4 \dagger}$, Lihong Qi ${ }^{2,5}$, Angelique Mahavongtrakul ${ }^{4}$, Ying Li ${ }^{4,6}$, Hong Li ${ }^{4,7}$, Jay Gong ${ }^{4}$, Reggie R. Fan ${ }^{4}$, Jin Li $i^{5,6}$, Michael Molmen, Travis A. Clark ${ }^{8}$, Dean Pavlick ${ }^{8}$, Garrett M. Frampton ${ }^{8}$, Brady Forcier ${ }^{8}$, Elizabeth H. Moore ${ }^{1}$, David K. Shelton ${ }^{1}$, Matthew Cooke ${ }^{8}$, Siraj M. Ali ${ }^{8}$, Vincent A. Miller ${ }^{8}$, Jeffrey P. Gregg ${ }^{2,9}$, Philip J. Stephens ${ }^{8}$ and Tianhong $\mathrm{Li}^{2,4,10^{*}}$

\begin{abstract}
Background: This retrospective study was undertaken to determine if the plasma circulating tumor DNA (ctDNA) level and tumor biological features in patients with advanced solid tumors affected the detection of genomic alterations (GAs) by a plasma ctDNA assay.

Method: Cell-free DNA (cfDNA) extracted from frozen plasma $(N=35)$ or fresh whole blood $(N=90)$ samples were subjected to a 62-gene hybrid capture-based next-generation sequencing assay FoundationACT. Concordance was analyzed for 51 matched FoundationACT and FoundationOne (tissue) cases. The maximum somatic allele frequency (MSAF) was used to estimate the amount of tumor fraction of cfDNA in each sample. The detection of GAs was correlated with the amount of cfDNA, MSAF, total tumor anatomic burden (dimensional sum), and total tumor metabolic burden (SUVmax sum) of the largest ten tumor lesions on PET/CT scans.
\end{abstract}

Results: FoundationACT detected GAs in 69 of 81 (85\%) cases with MSAF >0. Forty-two of 51 (82\%) cases had $\geq 1$ concordance GAs matched with FoundationOne, and 22 (52\%) matched to the National Comprehensive Cancer Network (NCCN)-recommended molecular targets. FoundationACT also detected 8 unique molecular targets, which changed the therapy in 7 (88\%) patients who did not have tumor rebiopsy or sufficient tumor DNA for genomic profiling assay. In all samples $(N=81)$, GAs were detected in plasma cfDNA from cancer patients with high MSAF quantity $(P=0.0006)$ or high tumor metabolic burden $(P=0.0006)$ regardless of cfDNA quantity $(P=0.2362)$.

Conclusion: This study supports the utility of using plasma-based genomic assays in cancer patients with high plasma MSAF level or high tumor metabolic burden.

Keywords: Next-generation sequencing (NGS), Plasma, Cell-free DNA (cfDNA), Circulating tumor DNA (ctDNA), Genomic alterations (GAs), Maximum somatic allele frequency (MSAF), Positron emission tomography (PET) scan, Maximum standardized uptake value (SUVmax)

\footnotetext{
*Correspondence: thli@ucdavis.edu

The study was presented in part at the 18th World Conference for the International Association for the Study of Lung Cancer (IASLC) in Yokohama, Japan on October 16, 2017. Abstract number: P1.07-013.

${ }^{\dagger}$ Cathy Zhou, Zilong Yuan and Weijie Ma contributed equally to this work.

${ }^{2}$ University of California Davis Comprehensive Cancer Center, Sacramento, CA, USA

${ }^{4}$ Division of Hematology and Oncology, Department of Internal Medicine University of California Davis School of Medicine, 4501 X Street, Suite 3016, Sacramento, CA 95817, USA

Full list of author information is available at the end of the article
}

(c) The Author(s). 2018 Open Access This article is distributed under the terms of the Creative Commons Attribution 4.0 International License (http://creativecommons.org/licenses/by/4.0/), which permits unrestricted use, distribution, and reproduction in any medium, provided you give appropriate credit to the original author(s) and the source, provide a link to the Creative Commons license, and indicate if changes were made. The Creative Commons Public Domain Dedication waiver (http://creativecommons.org/publicdomain/zero/1.0/) applies to the data made available in this article, unless otherwise stated. 


\section{Background}

The clinical application of multiplexed molecular biomarker assays has revolutionized cancer diagnosis and treatment, enabling the current era of precision cancer medicine [1-4]. Historically, the majority of current gold-standard biomarker assays were developed with archival tumor specimens obtained via invasive biopsies or surgical procedures $[1,5,6]$. Unfortunately, these assays can fail due to insufficient tumor specimen acquisition in up to $30 \%$ of reported cases [7-9]. Furthermore, biopsy may not be feasible in patients who are critically ill, whose tumors are in inaccessible locations, or need serial biopsies. Liquid biopsy and genomic profiling assays of plasma circulating tumor DNA (ctDNA) have been recommended by the College of American Pathologists (CAP), the International Association for the Study of Lung Cancer (IASLC), and the Association for Molecular Pathology (AMP) guidelines and are increasingly used in the clinic when tumor tissue is limited and/or insufficient for molecular testing [10-13]. Plasma ctDNA is defined as tumor-derived fragmented DNA in the blood that is not associated with cells. Plasma ctDNA should not be confused with cell-free DNA (cfDNA), which refers to DNA that is freely circulating in the bloodstream from both tumor and non-tumor origin. The detection of plasma cfDNA and/or ctDNA in cancer patients has been correlated with high tumor stage [14, 15], metastasis [14], poor prognosis [16, 17], treatment response $[18,19]$, and recurrence $[20,21]$. Alterations in the amount of ctDNA can reflect the dynamic changes of tumor metabolic burden during the disease course [22, 23]. Liquid biopsy has the advantages of being less or non-invasive with shorter turnaround time and less cost, while providing a temporal measurement of tumor burden and more fully capturing the landscape of tumor heterogeneity. However, the concordance rate of detected GAs between tissue and blood tumor genomic profiling assays varies significantly in reported studies [24-27]. While comparisons have been mostly focused on different analytic platforms, little attention has been paid to the unique tumor components needed for tissue and plasma tumor DNA. The sensitivity of detecting GAs and mutation allele frequencies (MAFs) in archived tissue is directly related to the absolute number and proportion of tumor cells present and extracted in the studied specimens [28]. Currently, plasma cfDNA from cancer patients, which includes both ctDNA and DNA from normal cells, has been used as a tumor resource in clinical assays for genomic profiling $[29,30]$. The sensitivity of detecting GAs in plasma samples is presumably affected by the steady-state level of plasma ctDNA shed by viable tumor cells into the blood, its metabolism in the plasma, and its percentage in relation to the total amount of plasma cfDNA. cfDNA levels are quantified by polymerase chain reaction (PCR) correlated with SUVmax in patients with non-small-cell lung cancer (NSCLC) [31]. Little is known regarding the quantitative relationship between the relative and absolute level of ctDNA in the blood and the biological features of a tumor [32] and the impact of tumor metabolic burden on the successful detection of GAs using a NGS assay for plasma ctDNA in cancer patients [31,33].

Positron emission tomography with computed tomography (PET/CT) has been routinely used as a noninvasive imaging tool for tumor staging, treatment planning, and treatment evaluation [34-36]. PET/CT scans provide a functional assessment of cancer cells based on increased glucose uptake and glycolysis, which may even detect metabolic abnormalities before morphologic or anatomic alterations occur in tumors [37, 38]. The standardized uptake value (SUV) is a semi-quantitative measurement of the tissue fluoro-D-glucose (FDG) accumulation rate, and the maximum standardized uptake value (SUVmax) has been used in the routine clinical report as the most reproducible imaging biomarker that has diagnostic and prognostic value on PET/CT scan [39, 40]. Decreased FDG activity has been correlated with the decreased plasma ctDNA level and tumor response in only a few prior cases [23, 41]. We hypothesized that the detection of GAs in plasma ctDNA depends on the presence of a sufficient amount of ctDNA produced by metabolically viable tumors in patients with advanced solid tumors. The objective of this study was to determine if the detection of GAs using the FoundationACT assay is associated with the amount of plasma cfDNA, plasma ctDNA, total tumor anatomic burden, or total tumor metabolic burden in cancer patients.

\section{Methods}

\section{Patient population}

Figure 1 shows the study flow chart. This institutional review board (IRB) approved study (\#937274 at the University of California, Davis) retrospectively reviewed 125 consecutive patients with locally advanced or metastatic solid tumors who underwent FoundationACT testing between November 17, 2015, and April 17, 2017. Among 90 patients with available FoundationACT reports, 81 patients had detectable ctDNA as measured by MSAF $>0$ in this study and quantitative PET/CT scans that were performed at our institution within 45 days of blood sampling. Furthermore, 51 of these 81 (63\%) patients with no treatment between the tissue and liquid biopsies also had matched FoundationOne reports. The concordance GAs across the tissue and plasma assays was analyzed for all actionable molecular targets and the National Comprehensive Cancer Network (NCCN)-recommended molecular targets. The concordance rate of 


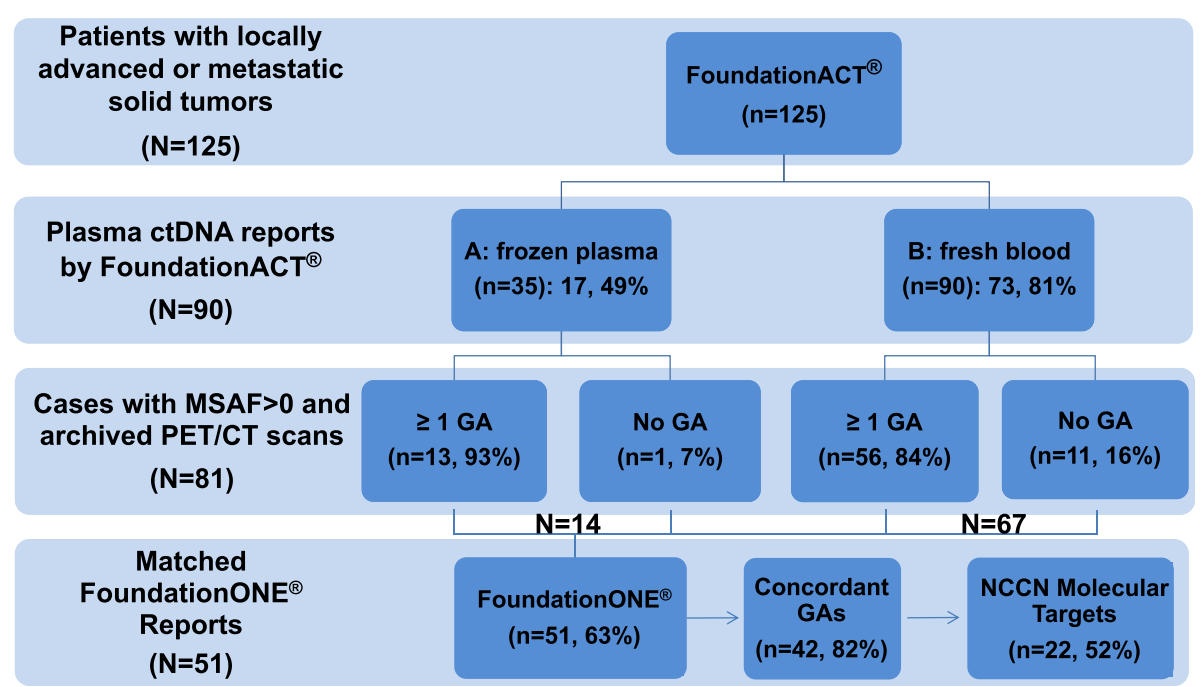

Fig. 1 Study schema. This study included 125 consecutive patients with locally advanced or metastatic solid tumors who underwent FoundationACT testing between November 17, 2015, and April 17, 2017. Among 90 patients with available FoundationACT reports, 81 patients had no interval treatment and ${ }^{18}$ F-FDG PET/CT scans performed at our institution within 45 days of blood sampling for imaging quantification analyses. The concordance rate of GA detection between 51 matched FoundationACT and FoundationOne cases was calculated and further analyzed for NCCN-recommended molecular targets in 42 patients

GAs detected between 51 matched FoundationACT and FoundationOne cases was calculated by dividing the number of concordant alterations by all the alterations (i.e., the concordant alterations plus unique alterations) detected by the FoundationOne assay. Only substitutions, insertion/deletions, and rearrangements were included; amplifications were not included.

\section{Preparation and quantification of plasma cell-free DNA}

Twenty milliliters (mLs) of peripheral whole blood were collected in K3 EDTA tubes for frozen samples (cohort A) or in K3 EDTA-containing Streck tubes (Cell-Free DNA BCT) for fresh blood (cohort B). Circulating cfDNA was recovered from $\sim 3 \mathrm{~mL}$ of frozen plasma (cohort A) or 4 to $5 \mathrm{~mL}$ of fresh plasma samples (cohort B) using the QIAamp Circulating Nucleic Acid Kit (Qiagen) and quantified using the Qubit 2.0 Fluorometer with dsDNA HS assay kits (Life Technologies, Carlsbad, CA). The tumor fraction of plasma cfDNA in each sample was estimated using the maximum somatic allele frequency (MSAF). MSAF is determined by calculating the allele fraction for all known somatic, likely somatic, and variant of unknown significance (VUS) alterations, excluding those alterations that are likely germline. The reported MSAF value for the clinical case was the highest allele frequency of the detected somatic variants. The logic utilizes both in-house and external references for germline information, including the Exome Aggregation Consortium (ExAC) database [12] and the Single Nucleotide Polymorphism Database (dbSNP) [42], as well as aneuploidy in the specimen's copy number profile to better assess MSAF. Importantly, each variant was subject to manual curation by a team of expert genomic analysts to remove sequence or alignment artifacts.

\section{Analytic validation of the FoundationACT ctDNA assay}

All samples with at least 20 ng cfDNA (20-100 ng) were subjected to the hybrid capture-based NGS (FoundationACT) assay performed at a Clinical Laboratory Improvement Amendments (CLIA)-certified, College of American Pathologists (CAP)-accredited, New York State-approved laboratory (Foundation Medicine, Inc). This assay identified four classes of genomic alterations: base substitutions, small insertions and deletions (indels), copy number variations, and rearrangements/ fusions. The target region includes a total of 62 genes, with 61 genes sequenced across all exons and 6 genes across introns commonly involved in rearrangements $[11,43]$. The FoundationACT assay has a sensitivity of $\geq$ 99.3\% and a positive predictive value (PPV) of $100 \%$ for base substitutions at allele frequency (AF) $>0.4 \%$, a sensitivity of $\geq 98.5 \%$, and a PPV of $>100 \%$ for insertion/deletions and a sensitivity of $>99 \%$ and a PPV of $98.0 \%$ for rearrangements at $\mathrm{AF}>1.0 \%$ [29]. Concordance rate was calculated by comparing GAs present in both FoundationACT and FoundationOne. Table 1 summarizes the genes tested in each assay.

\section{$\mathrm{PET} / \mathrm{CT}$ data acquisition and image analysis}

All PET/CT studies were performed on a Discovery 690 scanner (General Electric Company). After fasting for at least $6 \mathrm{~h}$, patients with glucose levels below $200 \mathrm{mg} / \mathrm{dL}$ 
Table 1 Comparison between targeted cancer genes tested in FoundationOne (FOne) $(n=315)$ test and FoundationACT (FACT) ( $n=62)$ assays

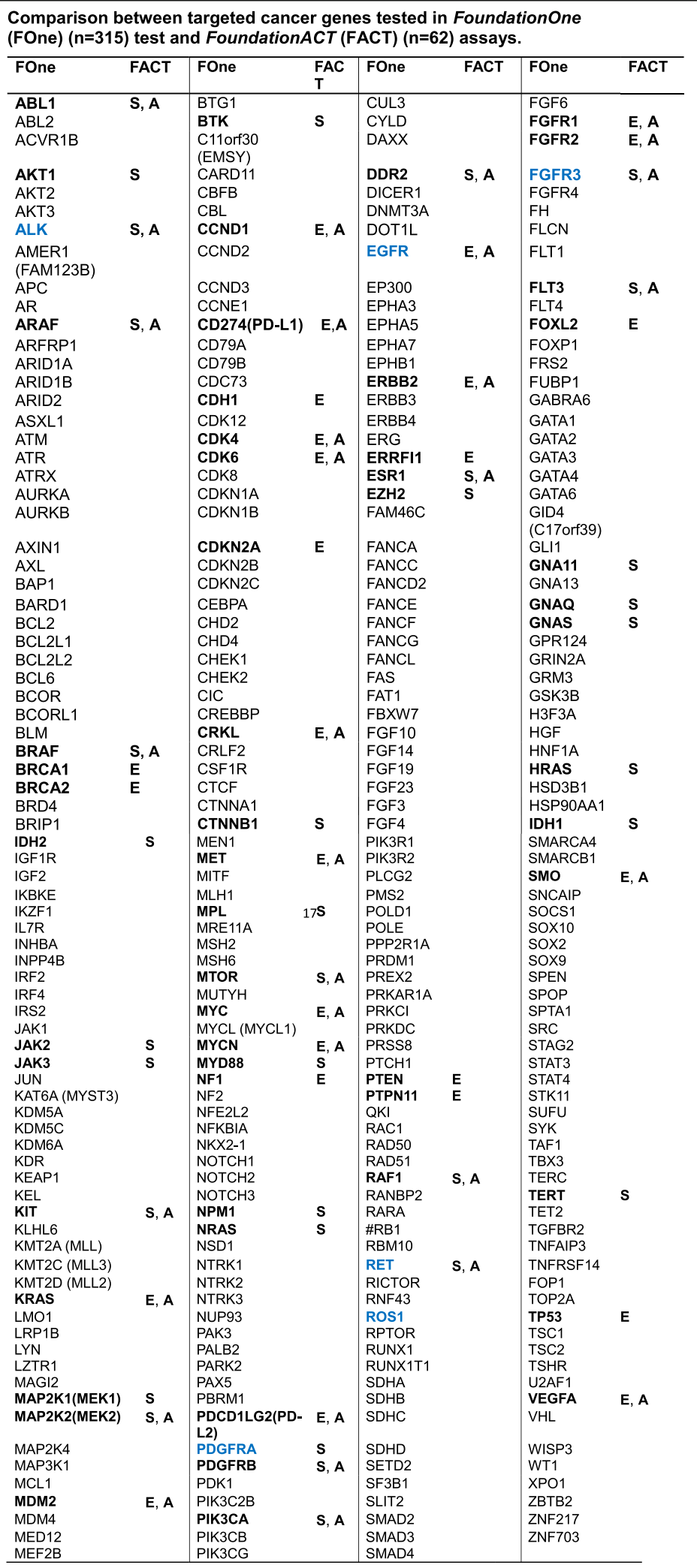

Bold highlights the genes that are tested in both FoundationACT and FoundationOne. $E$, genes with entire coding sequence coverage ( $n=27$ ); $S$, genes with selected, critical exon coverage. Blue highlights the rearranged genes tested in both FoundationACT and FoundationOne assays ( $n=6)$. $A$, genes that were evaluable for copy number amplification 
Table 2 Patient demographics and sample information

\begin{tabular}{llll}
\hline & $\begin{array}{l}\text { Group A } \\
(N=14)\end{array}$ & $\begin{array}{l}\text { Group B } \\
(N=67)\end{array}$ & $\begin{array}{l}\text { Total } \\
(N=81)\end{array}$ \\
\hline Type of specimen & Frozen plasma & Fresh whole blood & All samples \\
Age: median (range) & $68(44-73)$ & $67(45-93)$ & $67(44-93)$ \\
Gender: female N (\%) & $9(64 \%)$ & $46(69 \%)$ & $55(68 \%)$ \\
Race/ethnicity: N (\%) & & & \\
Caucasian & $8(57 \%)$ & $43(64 \%)$ & $51(63 \%)$ \\
Asian & $2(14 \%)$ & $13(19 \%)$ & $15(19 \%)$ \\
Hispanic & $2(14 \%)$ & $6(9 \%)$ & $8(10 \%)$ \\
African American & $2(14 \%)$ & $5(7 \%)$ & $7(9 \%)$ \\
Cancer type/histology: & $N(\%)$ & & $42(52 \%)$ \\
LUAD & $2(14 \%)$ & $40(60 \%)$ & $17(21 \%)$ \\
LUSC & $9(64 \%)$ & $8(12 \%)$ & $16(20 \%)$ \\
Breast & $3(21 \%)$ & $13(19 \%)$ & $6(7 \%)$ \\
Other cancer types* & 0 & $6(9 \%)$ &
\end{tabular}

*Other cancer types include lung small cell carcinoma $(n=2)$; lung large cell neuroendocrine $(n=1)$; ovarian, adenocarcinoma $(n=2)$; prostate, adenocarcinoma $(n=1)$ LUAD lung adenocarcinoma, LUSC lung squamous cell carcinoma

were administered $10 \mathrm{mCi}$ of 2-deoxy-2-[fluorine-18]fluoro-D-glucose $\left({ }^{18} \mathrm{~F}-\mathrm{FDG}\right)$ and allowed to rest quietly for a period of $60 \mathrm{~min}$. Patients were then scanned from the head to mid-thigh, followed by 3D PET emission data collection, reconstructed using an ordered subset expectation maximization algorithm (2 subsets, 24 iterations) and CT-based attenuation correction. At least two readers who were blinded to the clinical and genomic data reviewed and verified the tumor lesions on each clinical report. While Response Evaluation Criteria in Solid Tumors (RECIST) version 1.1 limits measurable lesions to $\leq 2$ per organ and $\leq 5$ lesions in total to evaluate treatment response [44], we measured the dimension and metabolic activity of up to ten of the most prominent primary and metastatic lesions. The total tumor anatomic burden was defined as the sum of the lesion diameters, and the tumor metabolic activity was estimated by the sum of the SUVmax values.

\section{Statistical analysis}

All the known and likely somatic alterations, substitutions, insertions/deletions, and rearrangements identified (designated as genomic alterations, GAs) in FoundationACT were used for the analysis. All data were summarized as the mean \pm standard deviation (SD). Descriptive statistics for continuous and categorical variables were stratified by GA status. The two-sample $t$ test was used for continuous variables. All analyses were conducted using SAS, university edition $2.5 \quad 9.4 \quad \mathrm{M} 4$ (SAS Institute, Cary, NC), and figures were made using GraphPad Prism software (Version 7.03). All statistical tests were two-sided and a $P$ value less than 0.05 was considered statistically significant.

\section{Results}

\section{Patient characteristics}

Patient demographics and disease characteristics are summarized in Table 2. Of the entire study population $(N=81)$, the median age was 67 years (range 44-93) with $55(68 \%)$ females. Fifty-three (63\%) patients were Caucasian, 15 (19\%) were Hispanic, 8 (10\%) were Asian, and 7 (9\%) were African American. Cancer types included

Table 3 GAs and factors affect the detection of GAs in the plasma ctDNA assay

\begin{tabular}{|c|c|c|c|}
\hline FoundationACT & Group A $(N=14)$ & Group B $(N=67)$ & Total $(N=81)$ \\
\hline Specimen type & Frozen plasma & Fresh whole blood & All samples \\
\hline Volume (mL) & $\sim 3.0$ & $8.5(5.5-11.5)$ & $8.0(3.0-11.5)$ \\
\hline cfDNA (ng/mL) & $2.5 \pm 5.0$ & $14.2 \pm 32.2$ & $P=0.023$ \\
\hline $\mathrm{GA} \geq 1$ & $13(93 \%)$ & $56(84 \%)$ & $69(85 \%)$ \\
\hline Total number of GAs (average/case, range) & 49 (3.5/case; 1-9) & 166 (2.5/case; 1-11) & 215 (2.7/case; 1-11) \\
\hline Base substitutions & $36(73 \%)$ & $118(71 \%)$ & $154(72 \%)$ \\
\hline Insertions/deletions & $8(16 \%)$ & $26(16 \%)$ & $34(16 \%)$ \\
\hline Amplifications & $1(2 \%)$ & $13(8 \%)$ & $14(7 \%)$ \\
\hline Rearrangements/fusions & $4(8 \%)$ & $9(5 \%)$ & $13(6 \%)$ \\
\hline $\begin{array}{l}\mathrm{cfDNA}(\text { mean } \pm \mathrm{SD}) \mathrm{ng} / \mathrm{mL} ;(\mathrm{GA} \geq 1 \text { vs } \\
\mathrm{GA}=0 \text { ) }\end{array}$ & $3.1 \pm 5.9$ vs $0.3 \pm 0.1(P=0.5293)$ & $\begin{array}{l}8.6 \pm 18.1 \text { Vs } 18.9 \pm 51.6 \\
(P=0.2314)\end{array}$ & $\begin{array}{l}7.6 \pm 16.7 \text { vs } 16.3 \pm 47.3 \\
(P=0.2362)\end{array}$ \\
\hline MSAF (mean $\pm S D) ;(G A \geq 1$ vs $G A=0)$ & $\begin{array}{l}0.0648 \pm 0.0823 \text { vs } 0.0005 \pm \\
0.0007(P=0.3062)\end{array}$ & $\begin{array}{l}0.1219 \pm 0.2031 \text { vs } 0.0003 \pm \\
0.0009(P=0.0432)\end{array}$ & $\begin{array}{l}0.1117 \pm 0.1880 \text { vs } 0.0003 \pm \\
0.0009(P=0.0304)\end{array}$ \\
\hline $\begin{array}{l}\text { Tumor burden by RECIST V1.1 cm (GA } \geq 1 \text { vs } \\
\mathrm{GA}=0)(\text { mean } \pm \mathrm{SD})\end{array}$ & $\begin{array}{l}7.6 \pm 6.4 \text { vs } 12.0 \pm 12.0 \\
(P=0.4610)\end{array}$ & $\begin{array}{l}9.8 \pm 5.8 \text { vs } 5.7 \pm 3.4 \\
(P=0.0292)\end{array}$ & $\begin{array}{l}9.4 \pm 5.9 \text { vs } 6.6 \pm 5.3 \\
(P=0.1301)\end{array}$ \\
\hline $\begin{array}{l}\text { Tumor metabolic activity by SUVmax mg/dL } \\
(G A \geq 1 \text { vs } G A=0)(\text { mean } \pm S D)\end{array}$ & $\begin{array}{l}51.1 \pm 34.8 \text { vs } 31.2 \pm 30.7 \\
(P=0.4772)\end{array}$ & $\begin{array}{l}48.1 \pm 29.5 \text { vs } 14.3 \pm 12.6 \\
(P=0.0006)\end{array}$ & $\begin{array}{l}48.6 \pm 30.2 \text { vs } 16.9 \pm 15.8 \\
(P=0.0006)\end{array}$ \\
\hline
\end{tabular}

GAs genomic alterations, cfDNA cell-free DNA, MSAF maximum somatic allele frequency, SUVmax maximum standardized uptake value 
predominantly lung adenocarcinoma (LUAD, $n=42$, $52 \%$ ), lung squamous cell carcinoma (LUSC, $n=17,21 \%$ ), and breast cancer $(n=16,20 \%)$.

\section{Detection of GAs in plasma ctDNA}

The yield of plasma cfDNA was highly variable among cancer patients and was significantly higher in fresh blood group compared to frozen plasma group $(14.2 \pm 32.2$ vs $2.5 \pm 5.0 \mathrm{ng} / \mathrm{mL}, P=0.023)$ (Table 3$)$. Of note, lower volumes of plasma were used in the frozen plasma group vs fresh blood group (3.0 vs $8.5 \mathrm{ml}$ ). A total of $215 \mathrm{GAs}$ were detected in 81 patients, with an average of $2.7 \mathrm{GAs}$ per sample (range 1-11), including 154 (72\%) base substitutions,
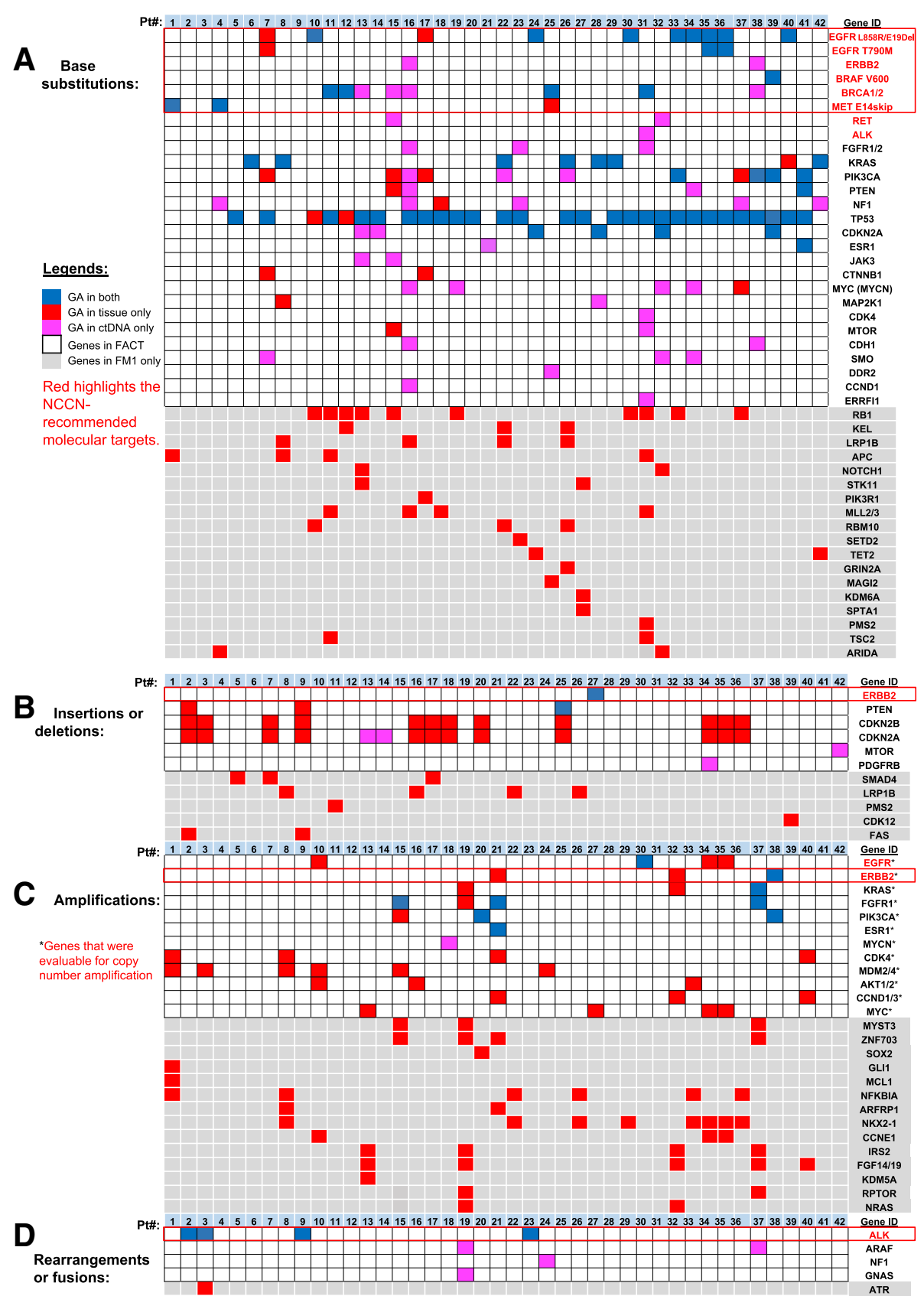

Fig. 2 Genomic alterations (GAs) and concordance of NCCN-recommended molecular targets detected by both FoundationACT and FoundationOne assays in 42 patients with advanced solid tumors. GAs in base substitutions (A), insertions or deletions (B), amplifications (C) or rearrangements (D) detected in patients with detectable ctDNA (i.e., MSAF > 0) are shown. Concordant/shared GAs are in blue, GA found only in tissue are in red, and GA found only in ctDNA are in pink. Genes that were only included in tissue (FoundationOne) were shaded in gray. Red color highlights the NCCN-recommended test genes, and red box highlights the NCCN-recommended molecular targets 
34 (16\%) insertions/deletions, 14 (7\%) amplifications, and $13(6 \%)$ rearrangements/fusions (Table 3).

FoundationACT detected GAs in 69 (77\%) patients $(N=90)$. When only considering samples with MSAF $>0$, FoundationACT detected GAs in 69 (85\%) samples $(N=81): 13(93 \%)$ in the frozen plasma group and $56(84 \%)$ in the fresh blood group. Fifty-one of these 69 (74\%) cases have matched FoundationOne reports (Fig. 1). Figure 2 provides the detail of each genomic alteration detected by FoundationOne only, FoundationACT only, or both. Similar to a recent report [45], there were more concordance GAs in base substitutions in TP53 (93\%), KRAS (88\%), EGFR (77\%), and PIK3CA (50\%) genes (Fig. 2a, blue) than genes in the insertions or deletions, amplifications, or rearrangements (Fig. 2b-d) in our dataset. FoundationOne (gray) detected more GAs (in red) as there were more genes tested in FoundationOne (gray shade) than FoundationACT. Of 51 patients with matched FoundationOne and FoundationACT reports, $42(82 \%)$ patients had at least one concordance GAs, which included 20 (48\%) patients with non-NCCNrecommended and $22(52 \%)$ patients with NCCN-recommended (red boxes in Fig. 2) molecular targets. FoundationACT detected 8 unique and 22 concordant GAs, with an overall concordance of $81 \%$ (range $67 \%-100 \%$ ) (Table 4). Of 8 unique GAs identified by FoundationACT only, the liquid biopsy genomic data led to a change in the clinical care with clinical benefit in 7 (88\%) patients who could not have tumor rebiopsy or sufficient tumor DNA for genomic profiling assay.

Twelve (15\%) cases had no detected ctDNA (i.e., MSAF $=0$ ) and no detectable GA. Table 5 summarizes the demographic and clinical information of these 12 cases, which included 6 (50\%) were in complete remission (CR), 1 (8.3\%) had partial response (PR), 3 (33\%) had small volume, stable or indolent disease, and 2
(16.7\%) had low volume progressive disease (PD). These data showed that cases with no ctDNA measured by MSAF correlated well with the relatively indolent disease. MSAF is particularly helpful to identify these cases with cfDNA mainly from non-cancerous sources, such as cancer patients who had a putative germline mutation (patient 7 and 8; both mutations were present in the corresponding tissue tumor DNA by FoundationOne), infection (patient 8 and 9), or non-infectious, immunerelated pneumonitis (patient 6 and Fig. 3) [46]. After first blood draw (Fig. 3A(a)) and PET scan (Fig. 3B(i)), patient 6 received several cycles of chemotherapy and three doses of nivolumab before chest CT scan 6 months later (Fig. $3 \mathrm{~B}$ (ii). Although there was no treatment between CT scan (Fig. 3B(ii)) and blood collection (Fig. 3A(b)) and CT scan (Fig. 3 B(iii)) about 1 month apart, the activated, potent immune response in patient 6 led to complete remission (CR) of tumors by radiographic assessment at $\sim 3$ months (Fig. $3 \mathrm{~B}(\mathrm{iv})$ ) at which time blood was collected. Figure $3 \mathrm{C}$ summarizes the quantitative analysis of biomarkers and clinical response at each time point. Among these biomarkers, MSAF stands out as the most informative measurement of plasma tumor burden in the dynamic clinical scenarios for this patient. The patient remained in CR at 6 months (Fig. $3 \mathrm{~B}(\mathrm{v})$ ) and 3-year clinical follow-up at the time of this submission (data not shown).

\section{Effect of tumor-specific factors on the detection of genomic alterations in plasma ctDNA}

We next determined the impact of four tumor-specific factors on the ability to detect GAs by FoundationACT. The quantity of cfDNA did not affect the detection of GAs in both sample groups (Table 3). MSAF was significantly higher in $G A \geq 1$ versus $G A=0$ cohorts in the fresh blood specimens (Fig. 4a) and all samples (Fig. 4b). The amount of anatomic tumor burden by total RECIST V1.1 correlated with the detection of GAs in the fresh

Table 4 Concordance of NCCN-recommended molecular targets detected by both FoundationACT and FoundationOne assays in 42 patients with advanced solid tumors

\begin{tabular}{|c|c|c|c|c|c|}
\hline Tumor types & Genomic alterations & $\begin{array}{l}\text { No. concordance } \\
(N=22)\end{array}$ & $\begin{array}{l}\text { No. unique to } \\
\text { FoundationOne }(N=4)\end{array}$ & $\begin{array}{l}\% \text { concordance } \\
(N=26)\end{array}$ & $\begin{array}{l}\text { No. unique to } \\
\text { FoundationACT }(N=8)\end{array}$ \\
\hline \multirow[t]{6}{*}{$\operatorname{NSCLC}(N=33)$} & EGFR L858R and exon 19 deletions & 8 & 2 & $80 \%$ & 0 \\
\hline & EGFR T790 M & 2 & 1 & $67 \%$ & 0 \\
\hline & ALK rearrangements & 4 & 0 & $100 \%$ & 0 \\
\hline & BRAF V600 mutation & 1 & 0 & $100 \%$ & 0 \\
\hline & MET exon 14 skip site alterations & 2 & 1 & $67 \%$ & 0 \\
\hline & ERBB2 mutations & 0 & 0 & $100 \%$ & 2 \\
\hline \multirow[t]{2}{*}{ Breast $(N=7)$} & ERBB2 amplification or mutation & 1 & 0 & $100 \%$ & 1 \\
\hline & BRCA1/2 mutations & 2 & 0 & $100 \%$ & 4 \\
\hline Ovarian $(N=2)$ & BRCA1/2 mutations & 2 & 0 & $100 \%$ & 0 \\
\hline
\end{tabular}




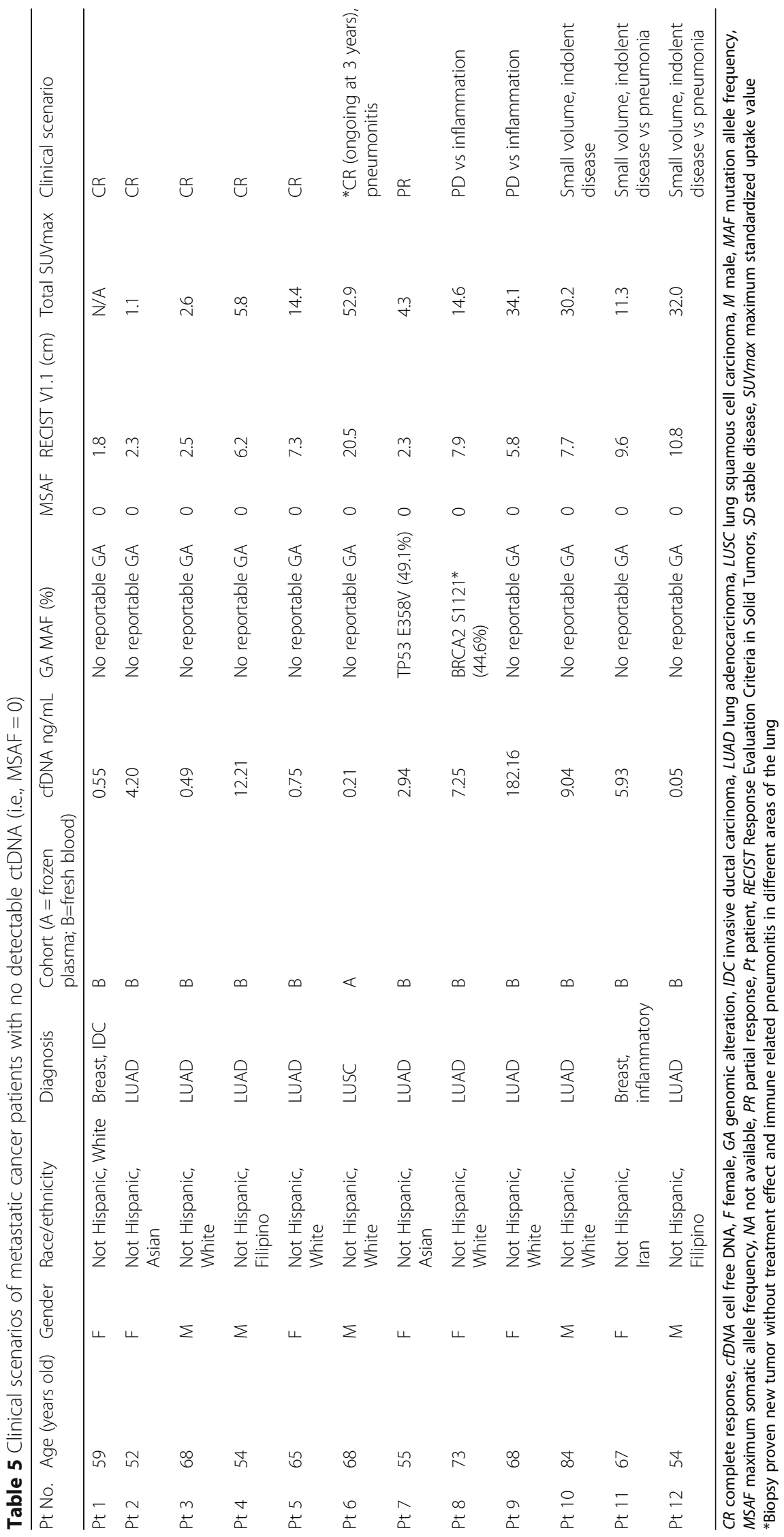


A Timeline:

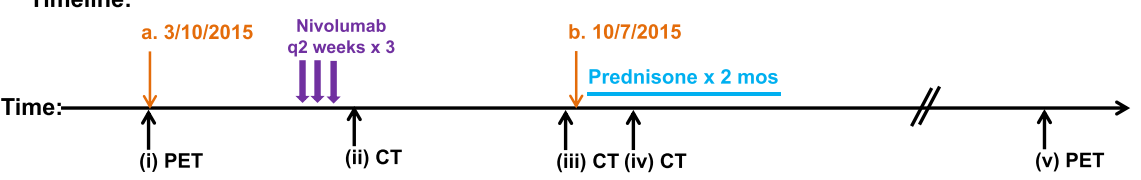

B Radiographic evaluation:

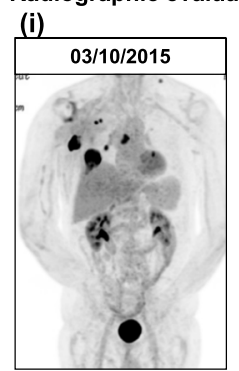

(ii) (iii)

(iii) (iv)

(iv)

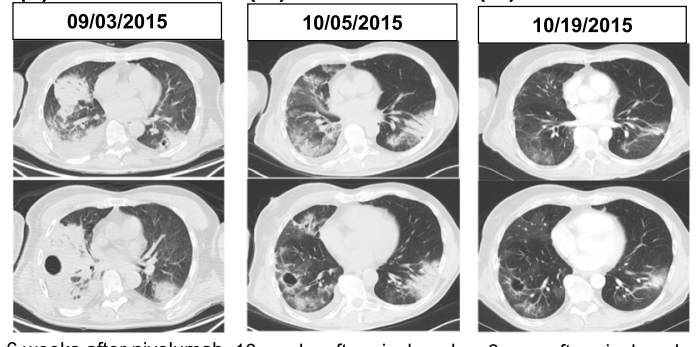

(v)

6 weeks after nivolumab 10 weeks after nivolumab $\sim 3$ mos after nivolumab 9 mos after nivolumab

C Quantitative analysis and clinical response:

\begin{tabular}{|c|c|c|c|c|c|}
\hline ID & Plasma cfDNA $\mathbf{( n g} / \mathbf{m L})$ & MSAF & RECIST V1.1 (cm) & Total SUVmax $(\mathbf{g} / \mathbf{m L})$ & Clinical scenarios \\
\hline a & 0.58 & 0.0111 & 16.2 & 44.3 & PD1 \\
\hline b & NA & NA & 17.2 & 52.1 & ${ }^{*}$ PD2, pneumonitis \\
\hline c & 0.21 & 0 & 10.7 & NA & Pneumonitis \\
\hline d & NA & NA & 12.2 & NA & CR \\
\hline e & NA & NA & 8.1 & 8.6 & CR \\
\hline
\end{tabular}

*Biopsy proven new tumor without treatment effect and immune related pneumonitis in different areas of the lung.

Fig. 3 MSAF is a valid tool for quantifying the tumor fraction of cfDNA. A representative case showing MSAF was a better tool than cfDNA and SUVmax to correlate with clinical response when the patient had non-infectious, immune-related pneumonitis. A Schema of the clinical course. B Radiographic evaluation: a 67-year-old Caucasian male, former four pack-year smoking history (quit 20 years ago), presented with refractory, lung squamous cell carcinoma (i). The patient developed non-productive cough and shortness of breath after three doses of nivolumab monotherapy and was found to have biopsy-proven, new tumor formation in right lower lobe as well as grade 3 pneumonitis in bilateral lung fields (ii) [46]. However, notable tumor shrinkage at several pre-existing tumors was observed. Blood drawn at 10 weeks later before the initiation of high dose steroids revealed non-detectable ctDNA (i.e., MSAF zero) (iii). Despite discontinuation of nivolumab and use of steroids for over 2 months for symptomatic pneumonitis, continued tumor response to a complete remission was evident by radiographic assessment by $\sim 3$ months (iv), which has been maintained at 9 months (v) and a recent 3-year follow-up (data not shown). C Quantitative analysis of biomarkers and clinical responses were summarized in table

blood group ( $9.8 \pm 5.8$ vs $5.7 \pm 3.4 \mathrm{~cm}, P=0.0292$; Fig. $4 \mathrm{c}$ ) but not in the all sample group $(9.4 \pm 5.9$ vs $6.6 \pm 5.3 \mathrm{~cm}$, $P=0.1301$; Fig. 4d). Tumor metabolic activity as measured by total SUVmax was significantly higher in GA $\geq$ 1 versus $\mathrm{GA}=0$ cohorts in the fresh blood specimens $(48.1 \pm 29.5$ vs $14.4 \pm 12.6 \mathrm{~g} / \mathrm{ml}, P=0.0006$; Fig. $4 \mathrm{e})$ and all samples $(48.6 \pm 30.1$ vs $16.9 \pm 15.8 \mathrm{~g} / \mathrm{mL}, P=$ 0.0006; Fig. 4f).

\section{Discussion}

Liquid biopsy using plasma cfDNA has been increasingly used as a minimally invasive alternative for tumor genomic profiling [47]. FoundationACT has been recently validated as a clinical NGS assay for genomic profiling of ctDNA derived from cfDNA in blood profiling [29, 30]. As ctDNA only comprises a small fraction of the total cfDNA, sensitive techniques are required to detect sequence alterations in ctDNA that frequently exist at low abundance. Similar to the recent reports using FoundationACT [11], we found that FoundationACT (plasma) assay detected GAs in the majority (75-77\%) of our cancer patients (Table 3). While many current efforts have been focused on the technology advances in increasing the sensitivity of plasma ctDNA assays [22], we used the bioinformatics tool MSAF to differentiate ctDNA from cfDNA. The sensitivity of detecting GAs was increased from $77 \%$ to $85 \%$ in samples with MSAF $>0$. The association of detecting GAs in samples with high MSAF and/or high tumor metabolic burden is intuitive. Patients with high tumor metabolic burden produced higher amounts of ctDNA, i.e., higher MSAF numbers (Fig. 4). Similarly, the significant association of detecting GAs with tumor metabolic burden likely reflects more metabolically active tumors shedding larger amounts of ctDNA in blood. These data support our hypothesis that sufficient plasma ctDNA shed from metabolically active tumors is required for the successful detection of GAs in plasma ctDNA. Further study is needed to define the threshold of SUVmax as a screening indicator for each ctDNA assay in histological and molecular homogenous subsets of cancer patients. 


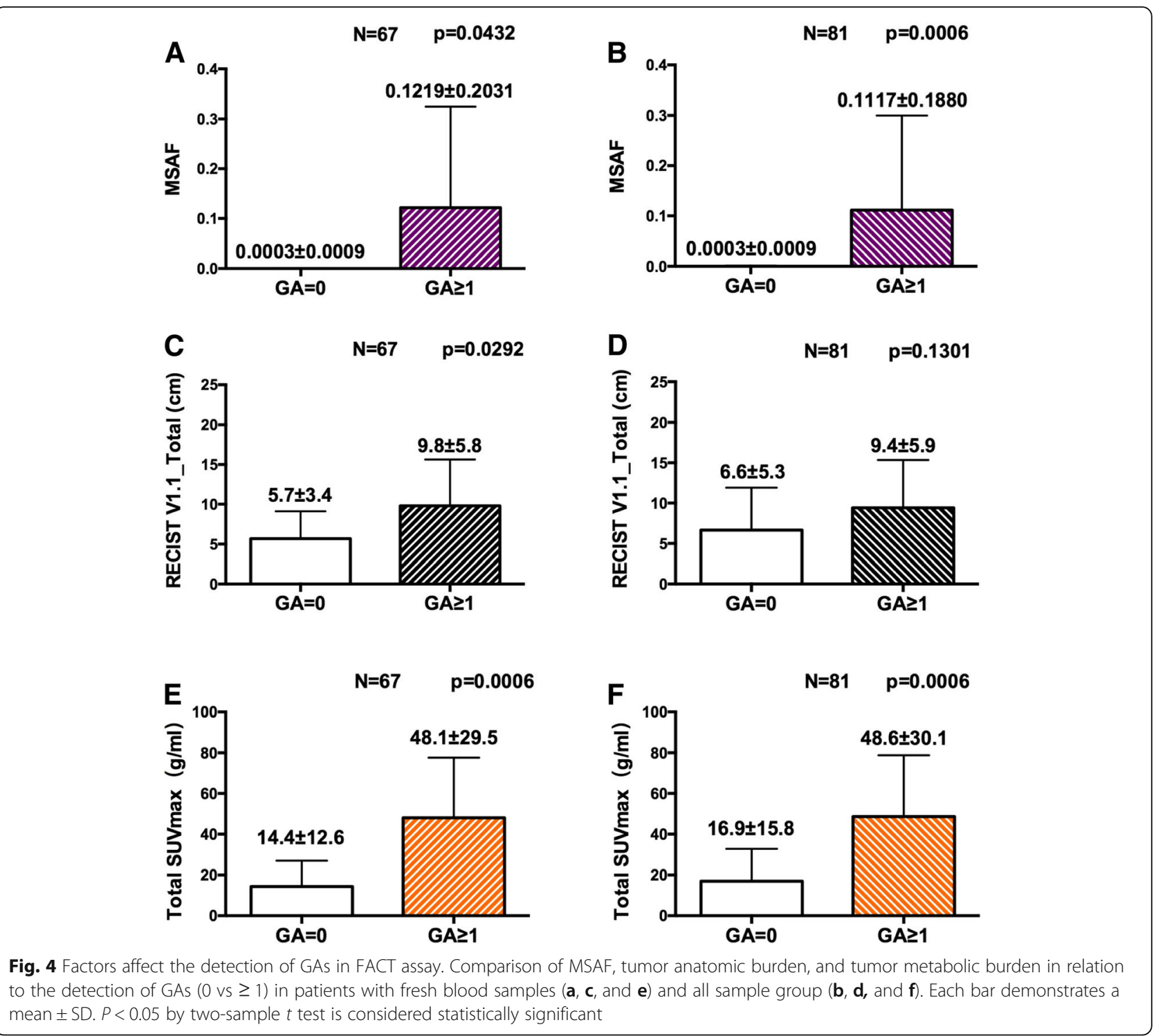

Moreover, MSAF is an effective bioinformatics tool for identifying the tumor fraction of cfDNA, which can contain a variable amount of germline or other non-tumor DNA (Table 5 and Fig. 3). Ongoing effort aims to define the cutoff of MSAF and further improve the clinical utility of MSAF in quantifying tumor-specific DNA in the plasma. To the best of our knowledge, this is the first study that has systemically and quantitatively evaluated the impact of cfDNA, ctDNA (as MSAF), tumor anatomic burden, and tumor metabolic burden on the ability to detect clinically actionable GAs using a clinical NGS assay for plasma ctDNA. In addition to our primary findings, FoundationACT also detected resistant mutations in two patients, one each with advanced NSCLC and breast cancer, which were not present on the tissue-based FoundationOne assay. This may reflect tumor heterogeneity and/or acquired resistant alteration following treatment, which could have important implications on future treatment selection.

Our study has several limitations. First, we included cancer patients with multiple cancer types at initial diagnosis and tumor progression who subsequently underwent different treatment regimens. The majority (73\%) of cases in this study was NSCLC. Further study should consider the impact of different molecular subtypes and cancer types on tumor metabolic activity that might affect the production of plasma ctDNA. Secondly, current clinical reports only use SUVmax as the PET biomarker and do not routinely measure SUVmax for all metabolically active tumor lesions, particularly in patients with extensive metastatic disease, which can significantly alter the value of the metabolic tumor sum. Conversely, our quantification of tumor metabolic burden was labor-intensive and subjected to observer 
variations. Further investigation should explore automated imaging tools to allow fast and objective quantification of the SUVmax sum and define the detection threshold in each cancer type for each assay for broad clinical application. Thirdly, FDG PET could not distinguish increased metabolism caused by tumor cells from that caused by infectious or noninfectious inflammation such as pneumonitis. Development of tumor-specific molecular imaging might improve the distinction of these clinical entities.

\section{Conclusion}

This study supports using tumor genomic profiling assay for detecting GAs in plasma ctDNA of cancer patients with metabolically active tumors. This knowledge is important for clinicians to select the appropriate patients for tumor genomic profiling assay using plasma ctDNA. Further studies are needed to optimize the clinical application of plasma ctDNA NGS assays in cancer types other than NSCLC.

\begin{abstract}
Abbreviations
AF: Allele frequency; CAP: College of American Pathologists; cfDNA: Cell-free DNA; CLIA: Clinical Laboratory Improvement Amendments; CR: Complete response; ctDNA: Circulating tumor DNA; dbSNP: Single Nucleotide Polymorphism Database; ExAC: Exome Aggregation Consortium; FDG: Fluorodeoxyglucose; GAs: Genomic alterations; LUAD: Lung adenocarcinoma; LUSC: Lung squamous cell carcinoma; MAF: Mutation allele frequency; MSAF: Maximum somatic allele frequency; NA: Not available; NCCN: National Comprehensive Cancer Network; NGS: Next-generation sequencing; NSCLC: Non-small-cell lung cancer; PD: Progressive disease; PET/ CT: Positron emission tomography with computed tomography; PPV: Positive predictive value; PR: Partial response; RECIST: Response Evaluation Criteria in Solid Tumors; SD: Stable disease; SD: Standard deviation; SUVmax: Maximum standardized uptake value; VUS: Variant of unknown significance
\end{abstract}

\section{Acknowledgements}

The authors would like to dedicate this work to the late Jeannine $\mathrm{H}$ Struckmeyer and her family and friends.

\section{Funding}

This study was funded by National Key R\&D Program of China (2016YFC0103400) (ZL) and Personalized Cancer Therapy Gift Fund (TL), P30 CA93373 for Biostatistics Shared Resource (LQ) and Genomics Shared Resource (JPG), and FMI-CTDNA-15 (ClinicalTrials.gov Identifier: NCT02620527) for ctDNA genomic assay.

\section{Availability of data and materials}

The dataset supporting the conclusions of this article is included within the article.

\section{Authors' contributions}

Drs. ZY, WM, and TL had full access to all the data in the study and take responsibility for the integrity of the data and the accuracy of the data analysis. TL contributed to the study concept and design. All authors contributed to the acquisition, analysis, or interpretation of data. WM, JG, ZY, $C Z$, and $T L$ contributed to the drafting of the manuscript. $Z Y, W M, L Q, J L$, and $T L$ contributed to the statistical analysis. All authors read and approved the final manuscript.

\section{Ethics approval and consent to participate}

The study was approved by the institutional review board (IRB) at the University of California, Davis (IRB ID: 937274).

\section{Consent for publication}

Not applicable

\section{Competing interests}

Jeffrey P. Gregg: Foundation Medicine $(H)$, AstraZeneca $(H)$, AstraZeneca (SAB), and BMS (C/A). Tianhong Li: NCI (RF), Pfizer (RF), Foundation Medicine $(C / A)$, Takada (C/A), and Puma (C/A). Michael Molmen: Foundation Medicine (E, OI); Travis A. Clark: Foundation Medicine (E, OI); Dean Pavlick: Foundation Medicine $(E, O I)$; Brady Forcier: Foundation Medicine $(E, O I)$; Garret $M$. Frampton: Foundation Medicine (E, OI, IP); Matthew Cooke Foundation Medicine (E, Ol); Siraj M. Ali Foundation Medicine (E, Ol); Vincent A. Miller: Foundation Medicine (E, OI); Philip J. Stephens: Foundation Medicine (E, $\mathrm{Ol}, \mathrm{IP})$.

(C/A) Consulting/advisory relationship; (RF) Research funding; (E) Employment; (ET) Expert testimony; (H) Honoraria received; (OI) Ownership interests; (IP) Intellectual property rights/ inventor/patent holder; (SAB) Scientific advisory board.

\section{Publisher's Note}

Springer Nature remains neutral with regard to jurisdictional claims in published maps and institutional affiliations.

\section{Author details}

'Department of Radiology, University of California Davis School of Medicine, Sacramento, CA, USA. ${ }^{2}$ University of California Davis Comprehensive Cancer Center, Sacramento, CA, USA. ${ }^{3}$ Department of Radiology, Hubei Cancer Hospital, Tongji Medical College, Huazhong University of Science and Technology, Wuhan, China. ${ }^{4}$ Division of Hematology and Oncology, Department of Internal Medicine University of California Davis School of Medicine, 4501 X Street, Suite 3016, Sacramento, CA 95817, USA.

${ }^{5}$ Department of Public Health Sciences, University of California, Davis, CA, USA. ${ }^{6}$ Currently Department of Medical Oncology, Chinese PLA General Hospital, Beijing, China. ${ }^{7}$ Currently Department of Geriatrics, Peking University First Hospital, Beijing, China. ${ }^{8}$ Foundation Medicine, Inc., Cambridge, MA, USA. ${ }^{9}$ Department of Pathology and Laboratory Medicine and Genomic Shared Resource, University of California Davis School of Medicine, Sacramento, CA, USA. ${ }^{10}$ Department of Internal Medicine, Veterans Affairs Northern California Health Care System, Mather, CA, USA.

Received: 4 September 2018 Accepted: 11 October 2018

Published online: 06 November 2018

\section{References}

1. Li T, Kung HJ, Mack PC, Gandara DR. Genotyping and genomic profiling of non-small-cell lung cancer: implications for current and future therapies. J Clin Oncol. 2013;31(8):1039-49.

2. Kalemkerian GP, Narula N, Kennedy EB, Biermann WA, Donington J, Leighl NB, Lew M, Pantelas J, Ramalingam SS, Reck M, Saqi A, Simoff M, Singh N, Sundaram B. Molecular testing guideline for the selection of patients with lung cancer for treatment with targeted tyrosine kinase inhibitors: American Society of Clinical Oncology Endorsement of the College of American Pathologists/International Association for the Study of Lung Cancer/ Association for Molecular Pathology Clinical Practice Guideline Update. J Clin Oncol. 2018. https://doi.org/10.1200/JCO.2017.76.7293.

3. Leong SM, Tan KM, Chua HW, Tan D, Fareda D, Osmany S, Li MH, Tucker S, Koay ES. Sampling circulating tumor cells for clinical benefits: how frequent? J Hematol Oncol. 2015;8:75.

4. Zhang YC, Zhou Q, Wu YL. The emerging roles of NGS-based liquid biopsy in non-small cell lung cancer. J Hematol Oncol. 2017;10(1):167.

5. Oncomine Dx Target Test FDA approval. 2017. https://www.accessdata.fda. gov/scripts/cdrh/cfdocs/cfpma/pma.cfm?id=P160045. Accessed 30 July 2018.

6. FDA announces approval, CMS proposes coverage of first breakthroughdesignated test to detect extensive number of cancer biomarkers. 2017. https://www.fda.gov/NewsEvents/Newsroom/PressAnnouncements/ucm5 87273.htm. Accessed 30 July 2018.

7. Lindeman NI, Cagle PT, Beasley MB, Chitale DA, Dacic S, Giaccone G, Jenkins RB, Kwiatkowski DJ, Saldivar JS, Squire J, Thunnissen E, Ladanyi M. Molecular testing guideline for selection of lung cancer patients for EGFR and ALK tyrosine kinase inhibitors: guideline from the College of American 
Pathologists, International Association for the Study of Lung Cancer, and Association for Molecular Pathology. J Thorac Oncol. 2013;8(7):823-59.

8. Jovelet C, lleana E, Le Deley MC, Motte N, Rosellini S, Romero A, Lefebvre C, Pedrero M, Pata-Merci N, Droin N, Deloger M, Massard C, Hollebecque A, Ferte C, Boichard A, Postel-Vinay S, Ngo-Camus M, De Baere T, Vielh P, Scoazec JY, Vassal G, Eggermont A, Andre F, Soria JC, Lacroix L. Circulating cellfree tumor DNA analysis of 50 genes by next-generation sequencing in the prospective MOSCATO trial. Clin Cancer Res. 2016:22(12):2960-8.

9. Couraud S, Vaca-Paniagua F, Villar S, Oliver J, Schuster T, Blanche H, Girard N, Tredaniel J, Guilleminault L, Gervais R, Prim N, Vincent M, Margery J, Larive S, Foucher P, Duvert B, Vallee M, Le Calvez-Kelm F, McKay J, Missy P, Morin F, Zalcman G, Olivier M, Souquet PJ, Bio Cl-i. Noninvasive diagnosis of actionable mutations by deep sequencing of circulating free DNA in lung cancer from never-smokers: a proof-of-concept study from BioCAST/IFCT1002. Clin Cancer Res. 2014:20(17):4613-24.

10. Wan JCM, Massie C, Garcia-Corbacho J, Mouliere F, Brenton JD, Caldas C, Pacey S, Baird R, Rosenfeld N. Liquid biopsies come of age: towards implementation of circulating tumour DNA. Nat Rev Cancer. 2017;17(4):223-38.

11. Chung JH, Pavlick D, Hartmaier R, Schrock AB, Young L, Forcier B, Ye P, Levin MK, Goldberg M, Burris H, Gay LM, Hoffman AD, Stephens PJ, Frampton GM, Lipson DM, Nguyen DM, Ganesan S, Park BH, Vahdat LT, Leyland-Jones B, Mughal TI, Pusztai L, O'Shaughnessy J, Miller VA, Ross JS, Ali SM. Hybrid capture-based genomic profiling of circulating tumor DNA from patients with estrogen receptor-positive metastatic breast cancer. Ann Oncol. 2017;28(11):2866-73.

12. Exome Aggregation Consortium. 2017. http://exac.broadinstitute.org/. Accessed 15 Jan 2018.

13. Lindeman NI, Cagle PT, Aisner DL, Arcila ME, Beasley MB, Bernicker EH, Colasacco C, Dacic S, Hirsch FR, Kerr K, Kwiatkowski DJ, Ladanyi M, Nowak JA, Sholl L, Temple-Smolkin R, Solomon B, Souter LH, Thunnissen E, Tsao $M S$, Ventura CB, Wynes MW, Yatabe Y. Updated molecular testing guideline for the selection of lung cancer patients for treatment with targeted tyrosine kinase inhibitors: guideline from the College of American Pathologists, the International Association for the Study of Lung Cancer, and the Association for Molecular Pathology. Arch Pathol Lab Med. 2018;142(3):321-46.

14. Bettegowda C, Sausen M, Leary RJ, Kinde I, Wang Y, Agrawal N, Bartlett BR, Wang H, Luber B, Alani RM, Antonarakis ES, Azad NS, Bardelli A, Brem H, Cameron JL, Lee CC, Fecher LA, Gallia GL, Gibbs P, Le D, Giuntoli RL, Goggins M, Hogarty MD, Holdhoff M, Hong SM, Jiao Y, Juhl HH, Kim JJ, Siravegna G, Laheru DA, et al. Detection of circulating tumor DNA in earlyand late-stage human malignancies. Sci Transl Med. 2014;6(224):224ra224.

15. Yang M, Topaloglu U, Petty WJ, Pagni M, Foley KL, Grant SC, Robinson M, Bitting RL, Thomas A, Alistar AT, Desnoyers RJ, Goodman M, Albright C, Porosnicu M, Vatca M, Qasem SA, DeYoung B, Kytola V, Nykter M, Chen K, Levine EA, Staren ED, D'Agostino RB Jr, Petro RM, Blackstock W, Powell BL, Abraham E, Pasche B, Zhang W. Circulating mutational portrait of cancer: manifestation of aggressive clonal events in both early and late stages. J Hematol Oncol. 2017:10(1):100

16. Oxnard GR, Thress KS, Alden RS, Lawrance R, Paweletz CP, Cantarini M, Yang $J C$, Barrett JC, Janne PA. Association between plasma genotyping and outcomes of treatment with osimertinib (AZD9291) in advanced nonsmall-cell lung cancer. J Clin Oncol. 2016;34(28):3375-82.

17. Mok TS, Wu YL, Ahn MJ, Garassino MC, Kim HR, Ramalingam SS, Shepherd FA, He Y, Akamatsu H, Theelen WS, Lee CK, Sebastian M, Templeton A, Mann H, Marotti M, Ghiorghiu S, Papadimitrakopoulou VA, Investigators A. Osimertinib or platinum-pemetrexed in EGFR T790M-positive lung cancer. N Engl J Med. 2017;376(7):629-40.

18. Jamal-Hanjani M, Wilson GA, McGranahan N, Birkbak NJ, Watkins TBK, Veeriah S, Shafi S, Johnson DH, Mitter R, Rosenthal R, Salm M, Horswell S, Escudero M, Matthews N, Rowan A, Chambers T, Moore DA, Turajlic S, Xu H, Lee SM, Forster MD, Ahmad T, Hiley CT, Abbosh C, Falzon M, Borg E, Marafioti T, Lawrence D, Hayward M, Kolvekar S, et al. Tracking the evolution of non-small-cell lung cancer. N Engl J Med. 2017;376(22): 2109-21.

19. Sun $W$, Yuan $X$, Tian $Y$, Wu H, Xu H, Hu G, Wu K. Non-invasive approaches to monitor EGFR-TKI treatment in non-small-cell lung cancer. J Hematol Oncol. 2015;8:95

20. Murphy DJ, Blyth KG. Predicting lung cancer recurrence from circulating tumour DNA. Commentary on 'Phylogenetic ctDNA analysis depicts earlystage lung cancer evolution'. Cell Death Differ. 2017;24(9):1473-4.
21. Ma W, Gong J, Shan J, Lewis D, Xiao W, Moore EH, Zhang Y, Hung J, Mans NZ, Wei S, Welborn J, Stollenwerk NS, Lam KS, Li T. Safety and efficacy of osimertinib in the treatment of a patient with metastatic lung cancer and concurrent somatic EGFR L858R and germline EGFR T790M mutations. JCO Precision Oncol. 2018;2:1-7.

22. Newman AM, Bratman SV, To J, Wynne JF, Eclov NC, Modlin LA, Liu CL, Neal JW, Wakelee HA, Merritt RE, Shrager JB, Loo BW Jr, Alizadeh AA, Diehn M. An ultrasensitive method for quantitating circulating tumor DNA with broad patient coverage. Nat Med. 2014;20(5):548-54.

23. Jamal-Hanjani M, Hackshaw A, Ngai Y, Shaw J, Dive C, Quezada S, Middleton G, de Bruin E, Le Quesne J, Shafi S, Falzon M, Horswell S, Blackhall F, Khan I, Janes S, Nicolson M, Lawrence D, Forster M, Fennell D, Lee SM, Lester J, Kerr K, Muller S, lles N, Smith S, Murugaesu N, Mitter R, Salm M, Stuart A, Matthews N, et al. Tracking genomic cancer evolution for precision medicine: the lung TRACERx study. PLoS Biol. 2014;12(7):e1001906.

24. Paweletz CP, Sacher AG, Raymond CK, Alden RS, O'Connell A, Mach SL, Kuang Y, Gandhi L, Kirschmeier P, English JM, Lim LP, Janne PA, Oxnard GR. Bias-corrected targeted next-generation sequencing for rapid, multiplexed detection of actionable alterations in cell-free DNA from advanced lung cancer patients. Clin Cancer Res. 2016;22(4):915-22.

25. Thompson JC, Yee SS, Troxel AB, Savitch SL, Fan R, Balli D, Lieberman DB, Morrissette JD, Evans TL, Bauml J, Aggarwal C, Kosteva JA, Alley E, Ciunci C, Cohen RB, Bagley S, Stonehouse-Lee S, Sherry VE, Gilbert E, Langer C, Vachani A, Carpenter EL. Detection of therapeutically targetable driver and resistance mutations in lung cancer patients by next-generation sequencing of cell-free circulating tumor DNA. Clin Cancer Res. 2016;22(23): $5772-82$.

26. Muller JN, Falk M, Talwar J, Neemann N, Mariotti E, Bertrand M, Zacherle T, Lakis S, Menon R, Gloeckner C, Tiemann M, Heukamp LC, Thomas RK, Griesinger F, Heuckmann JM. Concordance between comprehensive cancer genome profiling in plasma and tumor specimens. J Thorac Oncol. 2017; 12(10):1503-11.

27. Williams PM, Conley BA. Clinical application of liquid biopsies. JAMA Oncol, 2016;2(8):1003-5.

28. Frampton GM, Fichtenholtz A, Otto GA, Wang K, Downing SR, He J, SchnallLevin M, White J, Sanford EM, An P, Sun J, Juhn F, Brennan K, Iwanik K, Maillet A, Buell J, White E, Zhao M, Balasubramanian S, Terzic S, Richards T, Banning V, Garcia L, Mahoney K, Zwirko Z, Donahue A, Beltran H, Mosquera $J M$, Rubin MA, Dogan $S$, et al. Development and validation of a clinical cancer genomic profiling test based on massively parallel DNA sequencing. Nat Biotechnol. 2013;31(11):1023-31.

29. Clark TA, Chung JH, Kennedy M, Hughes JD, Chennagiri N, Lieber DS, Fendler B, Young L, Zhao M, Coyne M, Breese V, Young G, Donahue A, Pavlick D, Tsiros A, Brennan T, Zhong S, Mughal T, Bailey M, He J, Roels S, Frampton GM, Spoerke JM, Gendreau S, Lackner M, Schleifman E, Peters E, Ross JS, Ali SM, Miller VA, et al. Analytical validation of a hybrid capturebased next-generation sequencing clinical assay for genomic profiling of cell-free circulating tumor DNA. J Mol Diagn. 2018. https://doi.org/10.1016/j. jmoldx.2018.05.004.

30. Lanman RB, Mortimer SA, Zill OA, Sebisanovic D, Lopez R, Blau S, Collisson EA, Divers SG, Hoon DS, Kopetz ES, Lee J, Nikolinakos PG, Baca AM, Kermani BG, Eltoukhy $\mathrm{H}$, Talasaz A. Analytical and clinical validation of a digital sequencing panel for quantitative, highly accurate evaluation of cell-free circulating tumor DNA. PLoS One. 2015;10(10):e0140712.

31. Morbelli S, Alama A, Ferrarazzo G, Coco S, Genova C, Rijavec E, Bongioanni F, Biello F, Dal Bello MG, Barletta G, Massollo M, Vanni I, Piva R, Nieri A, Bauckneht M, Sambuceti G, Grossi F. Circulating tumor DNA reflects tumor metabolism rather than tumor burden in chemotherapy-naive patients with advanced non-small cell lung cancer: (18)F-FDG PET/CT study. J Nucl Med. 2017:58(11):1764-9.

32. Aravanis AM, Lee M, Klausner RD. Next-generation sequencing of circulating tumor DNA for early cancer detection. Cell. 2017;168(4):571-4.

33. Nygaard AD, Holdgaard PC, Spindler KL, Pallisgaard N, Jakobsen A. The correlation between cell-free DNA and tumour burden was estimated by PET/CT in patients with advanced NSCLC. Br J Cancer. 2014;110(2):363-8.

34. Fischer B, Lassen U, Mortensen J, Larsen S, Loft A, Bertelsen A, Ravn J, Clementsen P, Hogholm A, Larsen K, Rasmussen T, Keiding S, Dirksen A, Gerke O, Skov B, Steffensen I, Hansen H, Vilmann P, Jacobsen G, Backer V, Maltbaek N, Pedersen J, Madsen H, Nielsen H, Hojgaard L. Preoperative staging of lung cancer with combined PET-CT. N Engl J Med. 2009;361(1):32-9. 
35. Liao S, Penney BC, Zhang H, Suzuki K, Pu Y. Prognostic value of the quantitative metabolic volumetric measurement on 18F-FDG PET/CT in stage IV nonsurgical small-cell lung cancer. Acad Radiol. 2012;19(1):69-77.

36. Greco C, Rosenzweig K, Cascini GL, Tamburrini O. Current status of PET/CT for tumour volume definition in radiotherapy treatment planning for nonsmall cell lung cancer (NSCLC). Lung Cancer. 2007;57(2):125-34.

37. Townsend DW. Physical principles and technology of clinical PET imaging. Ann Acad Med Singap. 2004;33(2):133-45.

38. Lee P, Weerasuriya DK, Lavori PW, Quon A, Hara W, Maxim PG, Le QT, Wakelee HA, Donington JS, Graves EE, Loo BW Jr. Metabolic tumor burden predicts for disease progression and death in lung cancer. Int I Radiat Oncol Biol Phys. 2007;69(2):328-33.

39. Downey RJ, Akhurst T, Gonen M, Vincent A, Bains MS, Larson S, Rusch V. Preoperative F-18 fluorodeoxyglucose-positron emission tomography maximal standardized uptake value predicts survival after lung cancer resection. J Clin Oncol. 2004;22(16):3255-60.

40. Sasaki R, Komaki R, Macapinlac H, Erasmus J, Allen P, Forster K, Putnam JB, Herbst RS, Moran CA, Podoloff DA, Roth JA, Cox JD. [18F]fluorodeoxyglucose uptake by positron emission tomography predicts outcome of non-small-cell lung cancer. J Clin Oncol. 2005;23(6):1136-43.

41. Abbosh C, Birkbak NJ, Wilson GA, Jamal-Hanjani M, Constantin T, Salari R, Le Quesne J, Moore DA, Veeriah S, Rosenthal R, Marafioti T, Kirkizlar E, Watkins TBK, McGranahan N, Ward S, Martinson L, Riley J, Fraioli F, Al Bakir M, Gronroos E, Zambrana F, Endozo R, Bi WL, Fennessy FM, Sponer N, Johnson D, Laycock J, Shafi S, Czyzewska-Khan J, Rowan A, et al. Phylogenetic ctDNA analysis depicts early-stage lung cancer evolution. Nature. 2017;545(7655): 446-51

42. Single Nucleotide Polymorphism Database. 2017. https://www.ncbi.nlm.nih. gov/projects/SNP/. Accessed 15 Jan 2018.

43. FoundationACT ${ }^{\mathrm{M}} \mathrm{ctDNA}$ assay. 2017. http://foundationone.com/docs/ FoundationACT_AWhitePaper.pdf. Accessed 30 July 2018.

44. Eisenhauer EA, Therasse $P$, Bogaerts J, Schwartz $L H$, Sargent $D$, Ford $R$, Dancey J, Arbuck S, Gwyther S, Mooney M, Rubinstein L, Shankar L, Dodd L, Kaplan R, Lacombe D, Verweij J. New response evaluation criteria in solid tumours: revised RECIST guideline (version 1.1). Eur J Cancer. 2009;45(2):228-47.

45. Dagogo-Jack I, Bernicker E, Li T, Wang V, Ross JS, Young L, Stephens PJ, Chung J, Shaw AT, Ali SM, Miller VA, Schrock AB, Spigel DR, Ou S-HI. Genomic profiling of circulating tumor DNA (ctDNA) from patients (pts) with advanced non-small cell lung cancer (NSCLC). J Clin Oncol. 2017; 35(15_suppl):9025.

46. Li H, Ma W, Yoneda KY, Moore EH, Zhang Y, Pu LL, Frampton GM, Molmen M, Stephens PJ, Li T. Severe nivolumab-induced pneumonitis preceding durable clinical remission in a patient with refractory, metastatic lung squamous cell cancer: a case report. J Hematol Oncol. 2017;10(1):64.

47. Diaz LA Jr, Bardelli A. Liquid biopsies: genotyping circulating tumor DNA J Clin Oncol. 2014;32(6):579-86

Ready to submit your research? Choose BMC and benefit from:

- fast, convenient online submission

- thorough peer review by experienced researchers in your field

- rapid publication on acceptance

- support for research data, including large and complex data types

- gold Open Access which fosters wider collaboration and increased citations

- maximum visibility for your research: over $100 \mathrm{M}$ website views per year

At BMC, research is always in progress.

Learn more biomedcentral.com/submissions 